\title{
The Impact of PbF2-Based Glasses on Radiation Shielding and Mechanical Concepts: An Extensive Theoretical and Monte Carlo Simulation Study
}

\section{A. El-Denglawey}

College of University College at Turabah

Shams A.M. Issa

Al-Azhar University

Yasser B. Saddeek

Al-Azhar University

Huseyin 0. Tekin

University of Sharjah

Hesham M.H. Zakaly ( $\nabla$ h.m.zakaly@azhar.edu.eg )

Ural Federal University named after the first President of Russia B N Yeltsin Institute of Physics and

Technolog https://orcid.org/0000-0002-7645-9964

\section{Research Article}

Keywords: Lead-fluoride, mechanical competence, Monte Carlo, gamma shielding

Posted Date: March 16th, 2021

DOI: https://doi.org/10.21203/rs.3.rs-295736/v1

License: (9) This work is licensed under a Creative Commons Attribution 4.0 International License.

Read Full License

Version of Record: A version of this preprint was published at Journal of Inorganic and Organometallic Polymers and Materials on August 14th, 2021. See the published version at https://doi.org/10.1007/s10904-021-02088-w. 


\title{
The impact of PbF2-based glasses on radiation shielding and mechanical concepts: An extensive theoretical and Monte Carlo simulation study
}

\author{
A.El-Denglawey ${ }^{\mathrm{a}}$, Shams A.M. Issa ${ }^{\mathrm{b}, \mathrm{c}}$, Yasser B. Saddeek ${ }^{\mathrm{b}, \mathrm{d}}$, H.O.Tekin ${ }^{\mathrm{e}, \mathrm{f}}$, Hesham M.H. Zakaly ${ }^{\mathrm{b}, \mathrm{g} *}$ \\ a Department of Physics, College of University College at Turabah, Taif University, P.O. Box 11099, Taif \\ 21944, Saudi Arabia \\ ${ }^{\mathrm{b}}$ Physics Department, Faculty of Science, Al-Azhar University, Assiut 71524, Egypt \\ ${ }^{c}$ Physics Department, Faculty of Science, University of Tabuk, Tabuk 71451, Saudi Arabia \\ ${ }^{d}$ Department of Physics, College of Science in Zulf, Majmaah University, Al-Majmaah 11952 Saudi Arabia \\ e Medical Diagnostic Imaging Department, College of Health Sciences, University of Sharjah, Sharjah 27272, \\ United Arab Emirates \\ ${ }^{\mathrm{f}}$ Uskudar University, Medical Radiation Research Center (USMERA), 34672 Istanbul, Turkey \\ ${ }^{\mathrm{g}}$ Institute of Physics and Technology, Ural Federal University, Ekaterinburg 620000, Russia
}

*Corresponding author: (Hesham M.H. Zakaly): h.m.zakaly@gmail.com; Tel.: (+7 98264836 82)

\begin{abstract}
This work aimed to investigate the impact of Lead-fluoride based glasses via theoretical and simulation techniques on mechanical and radiation shielding parameters. Accordingly, a glass composition PbF2 blended with $\mathrm{TeO}_{2}-\mathrm{B}_{2} \mathrm{O}_{3}-\mathrm{Bi}_{2} \mathrm{O}_{3}$ glasses were synthesised by using melt-quenching method. Using Fluka Monte Carlo code, the radiation shielding properties have measured. Moreover. Comparatively higher density $\mathrm{PbF} 80=6.163 \mathrm{~g} / \mathrm{cm}^{3}$ with $80 \mathrm{~mol} \% \mathrm{Bi}_{2} \mathrm{O}_{3}$, greater $\mu, \mu_{\mathrm{m}}$ and Zeff and lower $\mathrm{T}_{1 / 2}, \lambda$, tenth value layer values achieved for $\mathrm{TeO}_{2}-\mathrm{B}_{2} \mathrm{O}_{3}-\mathrm{Bi}_{2} \mathrm{O}_{3} / \mathrm{PbF}_{2}$ glass pointed it out as the best shield of gamma. Besides, the computed effective removal cross-sections against fast neutrons $\left(\Sigma_{R}\right)$ observed that the $\mathrm{PbF} 80$ sample has commensurately greater with value $5.2954\left(\mathrm{~cm}^{-1}\right)$ The results observed that the variation $\mathrm{Bi}_{2} \mathrm{O}_{3} / \mathrm{PbF}_{2}$ improves the gamma protection ability of Lead-fluoride based glasses. The longitudinal modulus-L, shear modulus-S, bulk modulus-K, and Young's modulus-Y raised from 15.89 to $25.9-\mathrm{GPa}$, from 8.49 to $12.09-\mathrm{GPa}$, from 4.58 to $9.77-\mathrm{GPa}$, and from 15.74 to $25.69-\mathrm{GPa}$, respectively. The results indicate that the highest $\mathrm{Bi}_{2} \mathrm{O}_{3} / \mathrm{PbF}_{2}$ ratio encoded $\mathrm{PbF} 80$ has the best shielding and mechanical competence with measurable physical properties.
\end{abstract}

Keywords: Lead-fluoride, mechanical competence, Monte Carlo, gamma shielding. 


\section{Introduction}

It is well-known that various kinds of radiations such as gamma and $\mathrm{x}$-ray emission from natural background radiation sources and human-made synthetic radiation sources such as medical equipment, nuclear reactors as well as nuclear weapons. Depending on the radiation type and its energy, possible harmful effects are also revealed with previous works. When it comes to natural radiation, special precautions can be taken. These precautions could be listed as defining the amount of natural radioactivity and designing of living spaces properly. However, the case may be totally different in artificial radiation sources and its facilities. According to the well-known ALARA principle, it is highly wanted to save living tissues and environment from the ionising radiation. This protection proceeding is predominantly performed by decreasing the radiation to the safe level by utilising convenient shielding materials. Traditionally, concrete and lead are known as most used shielding materials due to their superior attenuation properties against gamma-ray and x-ray. Their employment could be performed not only in radiation staff equipment but also in shielding radiation facilities and radioactive sources. In addition to mentioned shield kinds, different materials like ceramics, polymers, concrete and alloys have been proposed as radiation shielding materials in previous studies [1-3]. Among the alternative shielding materials, glasses are utilised as radiation protection substances instead of traditional materials [4]. This is because glasses are reputed by high-level optical clarity and can be produced in varied sizes and shapes.

Heavy metal fluoride-based glasses (HMF) had favorable potentials in optical applications, specifically in the field of non-radiative loss infrared transmission and low phonon energy $[5,6]$. These features enable these glasses to achieve strong upconversion luminescence [7], i.e., these glasses can be considered as promising hosts for luminescent ions, solid state batteries [8], electrochemical applications [7], laser windows [9] and optical components with multiple functions [10]. Although HMF had interesting characteristics, but these glasses had low corrosion durability, chemical and thermal stability that restricted their synthesis and their use. Therefore, the oxyfluoride based glasses will be more suitable for updated use because these glasses consolidate the high phonon energies, the high chemical and thermal stability of oxide glasses with the interesting optical properties of fluoridebased glasses [11-14].

However, the TeO2-based glasses (TG) are the most suitable oxide glasses for consolidation with HMF because tellurite glasses had remarkable characteristics such as relatively low-phonon energy $[15,16]$. Also, TG had distinct refractive indices, high corrosion durability, thermal and chemical stability. Thus, 
blending TG with HMF is expected to give interesting features such as a wide range of optical transmittance with low optical losses, enhanced mechanical, chemical and thermal stability. Also, the new glasses can be considered as a good host for rare earth oxides to enhance their upconversion luminescence [17]. Among $\mathrm{HMF}, \mathrm{PbF} 2$ had a dual glass role, i.e., like $\mathrm{Bi}_{2} \mathrm{O}_{3}$, it had a glass former or modifier role. So, blending $\mathrm{PbF} 2$ and $\mathrm{Bi}_{2} \mathrm{O}_{3}$ into tellurite-based glasses network can form a wide range of stable glasses [18]. In continuation of other works [19,20], this study aims to evaluate the mechanical and radiation shielding parameters of a wide range of $\mathrm{PbF} 2$ blended with $\mathrm{TeO}_{2}-\mathrm{B}_{2} \mathrm{O}_{3}-\mathrm{Bi}_{2} \mathrm{O}_{3}$ glasses.

\section{Methods and Materials}

\subsection{Shielding properties}

It is well-known that if an attenuator specimen as shield located between the detector and the source, intensity of incident gamma-ray reduces exponentially due to Beer-Lambert law [21]:

$I=I_{o} e^{-\mu x}$

where the intensity of primary gamma is $\mathrm{I}_{0}$, and the intensity of transmitted gamma through the glass is I. Besides, $\mu$ indicates the linear attenuation coefficient of the energy of interest. The term of $\mathrm{x}$ is the thickness of attenuator sample. The MAC in the case of a compound, of glasses are estimated [22]:

$$
M A C=\sum_{i} w_{i}(M A C)_{i}
$$

Where, the weight fraction of the $\mathrm{i}^{\mathrm{th}}$ constitute elements is $\mathrm{w}_{\mathrm{i}}$.

The effective atomic number and effective electron density, depending on the total molecular cross_section $\left(\sigma_{\mathrm{t}}\right)$; total atomic cross-section $\left(\sigma_{\mathrm{a}}\right)$ and total electronic cross_section $\left(\sigma_{\mathrm{e}}\right)$; was used to measure the total effective atomic cross-section [23].

$$
\begin{aligned}
\sigma_{t} & =\frac{1}{N_{A}} \sum_{i} n_{i} A_{i}(M A C)_{i} \\
\sigma_{a} & =\frac{1}{N_{A}} \sum_{i} f_{i} A_{i}(M A C)_{i} \\
\sigma_{e} & =\frac{1}{N_{A}} \sum_{i} \frac{f_{i} A_{i}}{Z_{i}}(M A C)_{i}
\end{aligned}
$$




$$
\begin{aligned}
& Z_{e f f}=\frac{\sigma_{a}}{\sigma_{e}} \\
& N_{e f f}=\frac{(M A C)}{\sigma_{e}}
\end{aligned}
$$

The terms of $n_{i}, A_{i}, Z_{i}, f_{i}$ and $N_{A}$ are the number of atoms, atomic weight, atomic number, fractional abundance of $i^{\text {th }}$ element and Avogadro number. It's worth mentioning that a certain attenuator thickness can decrease the absorbed gamma intensity to $1 / 2$ of the premier radiation: this is called the half-value layer (HVL), and are acquired using the following equations [24,25]:

$$
H V L=\frac{\ln (2)}{L A C}
$$

An absorption of 0.368 of the incident gamma radiation observed by materials that have a thickness of one mean free path (MFP) [26]:

$$
M F P=\frac{1}{L A C}
$$

The exposure buildup factor (EBF) and energy absorption buildup factor (EABF) terms are also key parameters for seeing overall contributions to gamma rays' attenuation in material. G-P suitable approach was used to evaluate exposure buildup factor (EBF) and energy absorption buildup factor $(\mathrm{EABF})$, in the analysis. The specifics of our previous study can be found in literature elsewhere [2730].

\subsection{Simulation studies using FLUKA code}

Nine samples of glass were simulated using the FLUKA Monte Carlo code [28,31,32]. The FLUKA, is a simulation program used to estimate the Mass Attenuation Coefficient by obtaining photons passing through materials and an initial number of photons in the detector's volume. Besides, the USRBIN was used as a detector map to predict the photon flux inside the detector (Fig. 1). During the current simulation, the required card MATERIAL was attached to the COMPOUND card for sample identification. Composition, name, density, material number, etc. of the Complex were selected as a MATERIAL CARD. Three inches of $\times$ and three inches of a cylindrical NaI(Tl) detector was placed in a Pb-cylindrical collimator with these dimensions $(12,0.2,15) \mathrm{cm}$ outer, inner, length respectively. A USRTRACK scorecard (metric) described the NaI region as a fluctuation in the path length according to statistical error $(<0.1 \%)$, The total of elementary photons for simulation is about 10 million. LOWBIAS card requires asymmetric absorption and/or an energy cutoff during low energy neutron transport 
on a regional basis. A BEAM card determined particle's shape and energy; although, it produced to set a monoenergetic $(0.2 \mathrm{~cm}$ size $)$ photon with energies between 0.015 and $15 \mathrm{MeV}$ to determine the source beam. The BEAMPOS card made to adjust this beam source's orientation and position on the positive z-axis. The photon transmission power cut adjusted to an energy level of $10^{-7} \mathrm{GeV}$ using the EMFCUT card at low levels of energy. For modelling all glass samples, a cylindrical geometry with a 1.0 $\mathrm{cm}$ diameter and a thickness varying between 0.1 to $0.5 \mathrm{~cm}$ (based on the primary photon energy) was used. In all samples encoded PbF00, PbF10, PbF20, PbF30, PbF40, PbF50, PbF60, PbF70 and PbF80, a cylindrical geometry with a diameter of $1.0 \mathrm{~cm}$ and a thickness of 0.1 to $0.5 \mathrm{~cm}$ (depending on the energy of the primary photon) was used. The glass samples were formalised with a RPP body. It was denoted by $\min X-\max X, \min Y-\max Y$ and $\operatorname{minZ}$ - $\operatorname{maxZ}$, and boundaries parallel to the coordinate axis. In this geometry, the $\max X$ value (maxY value) and the $\min X$ value (minY value) were chosen as $+5 \mathrm{~cm}$ and $-5 \mathrm{~cm}$, respectively [33]. The target material is selected with a length of $15 \mathrm{~cm}$ and a width of various thicknesses with the obtained $\max \mathrm{Z}$ and min $\mathrm{z}$. After interacting with the sample, the photons were located in the detector volume. The size of a detector is covered with a lead collimator to prevent the identification of scattered photons.

\section{Results and discussions}

\subsection{Elastic parameters}

The values of the studied glass samples' density were in good agreement with those obtained earlier [18-20]. The rigidity of radiation shielding materials had a special interest. The structure of a shielding can be correlated to the rigidity, so, this correlation can determine the use of such a shielding. The rigidity of the glass shielding can be evaluated from determining the elastic moduli of such a shielding. The elastic moduli can be evaluated according to Makishima -Mackenzie model [34,35]. The bulk modulus $\left(\mathrm{K}_{\mathrm{mac}}\right)$ and Young's modulus $\left(\mathrm{Y}_{\mathrm{mac}}\right)$ in terms of the dissociation energy $\left(\mathrm{Gt}_{\mathrm{i}}\right)$, the mole fraction of the $\mathrm{i}^{\text {th }}$ oxide $\left(\mathrm{A}_{\mathrm{m}} \mathrm{O}_{\mathrm{n}}\right)$ in the glass sample $\left(\mathrm{x}_{\mathrm{i}}\right)$, and the ionic radii according to Pauling of the $\mathrm{i}^{\text {th }}$ cation $\left(\mathrm{R}_{\mathrm{A}}\right)$ and oxygen $\left(\mathrm{R}_{\mathrm{O}}\right)$ respectively as:

$$
\begin{aligned}
& K_{m a c}=100 V_{a}^{2} \sum_{i} G t_{i} x_{i} \\
& Y_{m a}=2 V_{t a} \sum_{i} G t_{i} x_{i}
\end{aligned}
$$




$$
V_{t a}=\frac{4 \rho \pi N_{A}}{3 M_{t}} \sum_{i}\left(m R_{A i}^{3}+n R_{O i}^{3}\right) x_{i}
$$

Where $N_{A}$ is Avogadro's number and $\rho$ is the density of the glass sample. Table 1 presents the values of the density and the former physical parameters.

El Agammy et al [19] reported on the dual role of $\mathrm{PbF} 2$ in tellurite-based glasses. At high concentrations of $\mathrm{PbF} 2, \mathrm{PbF} 2$ constructed its own network and behaves as a glass former. At these ratios of $\mathrm{PbF} 2$, the network of $\mathrm{PbF} 2-\mathrm{TeO} 2$ will be composed of $P b_{1 / 2}^{2+}\left[\mathrm{TeO}_{3+1}\right]^{-}$and $\mathrm{TeO}_{3 / 2} \mathrm{~F}$ structural units with two-non bridging oxygens. These arguments agree with studies on the role of PbO [36]. The incremental of $\mathrm{Bi}_{2} \mathrm{O}_{3}$ at the expense of $\mathrm{PbF}_{2}$ increases the density of the explored glasses as there is a difference between the atomic mass of $\mathrm{Bi}_{2} \mathrm{O}_{3}(465.959 \mathrm{~g} / \mathrm{mol})$ and atomic mass of $\mathrm{PbF} 2(245.197$ $\mathrm{g} / \mathrm{mol}$ ). Saddeek et al [18] reported on the formation of the concentrations of [BiO6] and [BiO3] structural units as the $\mathrm{Bi} 2 \mathrm{O} 3$ content increases. In the explored glasses, as the $\mathrm{Bi}_{2} \mathrm{O}_{3}$ content increases, the glass former role of $\mathrm{Bi}_{2} \mathrm{O}_{3}$ manifests itself in the presence of two formers glass with high field strength cations, namely, $\mathrm{TeO}_{2}$ and $\mathrm{B}_{2} \mathrm{O}_{3}$. This procedure will affect the elastic moduli of the explored glasses. According to the literature, the packing density and the dissociation energy of $\mathrm{Bi} 2 \mathrm{O} 3$ are $26.1 \times 10^{-6} \mathrm{~m}^{3} \mathrm{~mol}^{-1}$ and $31.6 \times 10^{9} \mathrm{~J} \mathrm{~m}^{-3}$, respectively [37], while those of PbF2 are $10.21 \times 10^{-6} \mathrm{~m}^{3} \mathrm{~mol}^{-1}$ and $23.21 \times 10^{9} \mathrm{~J} \mathrm{~m}^{-3}$, respectively [38-40], i.e., the bond strength of $\mathrm{Bi}-\mathrm{O}$ is larger than that of the $\mathrm{Pb}$ - F. The packing density and the dissociation energy are decisive parameters in determining the elastic moduli of the glasses according to Makishima -Mackenzie model.

Thus, the increase of $\mathrm{Bi} 2 \mathrm{O} 3$ will strengthen the lead telluro-borate network. The strength will be achieved by creating bridging oxygens that provided from the structural units of $\mathrm{Bi} 2 \mathrm{O} 3$. These oxygens converted $\mathrm{Pb}_{1 / 2}^{2+}\left[\mathrm{TeO}_{3+1}\right]^{-}$into TeO4 structural units. This process will compact the glass network and increase the density and increase the packing density and the dissociation energy of the explored network as tabulated in Table 1 and as shown in Fig. Therefore, the elastic moduli of the lead tellurobortae network will increase as shown in Figs. (and). The linear increase of the elastic moduli revealed the modifier role of $\mathrm{Bi} 2 \mathrm{O} 3$.

\subsection{Shielding parameters}

In this study, different types of glasses encoded PbF00, PbF10, PbF20, PbF30, PbF40, PbF50, PbF60, $\mathrm{PbF70}$, and PbF80 were evaluated by using Monte Carlo simulation methods in terms of gamma-ray attenuation competencies. The efficiency of a substance while subjected to gamma radiation is based 
on its elemental structure and density. For simulation studies, material properties of the examined sample should be taken into account. Recently, the shielding efficiency of glass shield samples was examined using Monte Carlo simulation. Figure 1 demonstrates the general setup for evaluating the attenuation properties of glass shielding products. The isotropic point source was mounted within a Lead $(\mathrm{Pb})$ plating shield. In addition to installing a collimator into the $\mathrm{Pb}$ block, a main gamma-ray beam was also used. For calculation of certain important parameters such as the linear attenuation coefficients $(\mu)$, mass attenuation coefficients $\left(\mu_{\mathrm{m}}\right)$, half-value layer $\left(\mathrm{T}_{1 / 2}\right)$ and mean free path $(\lambda)$, primary and secondary gamma-ray intensities, which are obtained from FLUKA output file were used. The Figure 2 shows the variance of linear attenuation coefficients of PbF00, PbF10, PbF20, PbF30, $\mathrm{PbF} 40, \mathrm{PbF} 50, \mathrm{PbF} 60, \mathrm{PbF70}$, and PbF80 samples at various photon energies from 0.015 to $15 \mathrm{MeV}$. The three most dominant interaction mechanisms explored in the figure are the Photoelectric Effect (PE), Compton Scattering (CS), and Pair Production (PP). When in low-energy zones, PE was shown to be the primary factor for absorption of gamma-rays [41]. The reduction was recorded in the same area. However, comparatively smooth functional decrements existed at mid and high frequency, gamma-band frequencies. CS and PP were strongest in the mid-level and high-level photon energy zones, respectively [42]. The effect being observed is characteristic of attenuators and is based on the association of incident photons with the substance's atomic structure. However, the results showed that PBF00 sample has the highest linear attenuation coefficients $(\mu)$ values at all photon energies. This can be explained by elemental composition and materials characteristic of PBF00 sample that caused for superior shielding competencies among the investigated glass shields. The term of mass attenuation coefficients $\left(\mu_{\mathrm{m}}\right)$ of an attenuator is a particular quantity that may be used for classification purposes of shields depending on the LAC value. Figure 3 (a-i) is a comprehensive demonstration between FLUKA general purpose Monte Carlo code and XCOM software. The figure depicts the variation of mass attenuation coefficient $\left(\mu_{\mathrm{m}}\right)$ values versus photon energy $(\mathrm{E})$ for glass samples, respectively. It is seen from the Figure $3(\mathrm{a}-\mathrm{i})$ that obtained $\mu \mathrm{m}$ values are in high accordance. Figure 4 was added into results to demonstrate the quantitative differences between the FLUKA and XCOM for Pb80 and Pb00 glass samples. It is seen from the Figure 4 that variation trend of $\mu_{\mathrm{m}}$ values is in similar attitude. This is a clear evidence for reliability of utilised Monte Carlo simulations considering the standard NIST data. However, some slight differences were also reported at some specific energies. The smooth differences are expected deviations since the FLUKA and XCOM database uses different approaches during the determination of mass attenuation coefficients. On the other hand, this behavior can be attributed to way of data providing since FLUKA uses individual simulation techniques, where the primary and 
secondary gamma-ray intensities are main quantities for the calculation of coefficient, whereas XCOM provides direct results from the NIST database [43]. By utilisation of linear attenuation coefficients, half value layer $\left(T_{1 / 2}\right)$ values of studied glass samples were determined. There is an inverse relationship between the $T_{1 / 2}$ and $\mu$ values. It means that the materials with higher $\mu$ values will have lower $T_{1 / 2}$ values at related energy values. In other words, one can say that the materials with higher $\mu$ values requires lower thicknesses to reduce the incident gamma-ray to its half. Figure 5 represents the variation of half-value layer $\left(\mathrm{T}_{1 / 2}\right)$ values with photon energy for glass samples. It can be observed from the figure that half value layers increased with increasing photon energy. This can be explained with gamma-ray material interaction facts that higher energy gamma-rays requires higher material thicknesses to be reduced to its half intensity. However, half value layer values are also critical parameters to distinguish the competencies of shielding materials. As previously discussed, PBF00 samples was reported with the highest linear attenuation coefficients. Therefore, one can expect that this sample will require the lowest thicknesses among the studied samples. This is clear in the Figure 5 that PBF00 sample has the lowest half value layer values at used photon energy values, whereas PBF80 has the highest. The aforementioned situation can also be linked with their sharp chemical compositions as well as material densities (i.e. the highest and the lowest). Figure 6 shows the variation of another vital shielding parameter namely mean free path $(\lambda)$ values with photon energy for glass samples. The term of mean free part is an essential parameter to define the average distance of gammarays that they can travel though the material. In the superior shielding materials, it can be expected to have lower distances that gamma-ray can travel thought the attenuator. The aforementioned situation is clearly seen in Figure 6 that PBF00 was noted with the lowest mean free path values. This can be also considered as an evidence for its superior gamma-ray shielding competencies among the all studied glass shields. Figure 7 shows the variation of $Z_{\text {eff }}$ values with photon energy for glass samples. The term of $Z_{\mathrm{eff}}$ is a handy parameter to assess the attenuation competencies of mixtures considering their substance elements with their individual atomic numbers $(Z)$. It is well-known that the elements with higher $\mathrm{Z}$ numbers have a remarkable advantage during the attenuation process of ionising gamma-rays. In parallel, it can be said that mixtures, which consist from substances with higher $\mathrm{Z}$ number, can attenuate the gamma-rays in better way. Considering the elemental compositions of studied glasses, it can be noted that the amount of high $\mathrm{Z}$ substances in PBF00 sample has caused for the existing situation, which can be clearly observed from the Figure 7. It can be said that PbF00 sample has the highest $Z_{\text {eff }}$ values at all photon energy values. Finally, it's worth mentioning that effective removal cross-sections against fast neutrons $\left(\Sigma_{R}\right)$ were also theoretically calculated for all glasses. This is a 
theoretical parameter that indicates the resistance potential of studied compositions against fast neutrons, which is directly depend on partial density and removal cross sections of substance elements in composition. The results showed that there is a synergistic relationship between the gamma-ray shielding competencies and effective removal cross-sections of PbF00 sample (see Figure 9). It can be noted that superior gamma-ray attenuator encoded $\mathrm{PbF} 00$ is also a potential neutron shield against fast neutrons.

\section{Conclusion}

this study aims to evaluate the mechanical and radiation shielding parameters of a wide range of $\mathrm{PbF}_{2}$ blended with $\mathrm{TeO}_{2}-\mathrm{B}_{2} \mathrm{O}_{3}-\mathrm{Bi}_{2} \mathrm{O}_{3}$ glasses. The different types of glasses encoded $\mathrm{PbF} 00, \mathrm{PbF} 10, \mathrm{PbF} 20$, $\mathrm{PbF} 30, \mathrm{PbF} 40, \mathrm{PbF} 50, \mathrm{PbF} 60, \mathrm{PbF} 70$, and $\mathrm{PbF} 80$ were evaluated by using Monte Carlo simulation methods in terms of gamma-ray attenuation competencies. The efficiency of a substance while subjected to gamma radiation is based on its elemental structure and density. Computational methods had computed the mass attenuation coefficients (MAC). The MAC values at $0.015 \mathrm{MeV}$, increase from 85.16 to $96.92\left(\mathrm{~cm}^{2} \mathrm{~g}^{-1}\right)$ as the $\mathrm{Bi}_{2} \mathrm{O}_{3} / \mathrm{PbF}_{2}$ ratio changed from 0 - $80 \mathrm{~mol} \_\%$, and the HVL values decrease from 1.93 to $1.66(\mathrm{~cm})$ at $1 \mathrm{MeV}$. The results indicate that the PbF80 glass sample with $80 \%$ mole $\mathrm{Bi}_{2} \mathrm{O}_{3}$ has the best mechanical competence and best in ability to block ionising radiation.

\section{Acknowledgement}

Taif University Researchers Supporting Project number (TURSP-2020/45) Taif University, Taif, Saudi Arabia.

\section{References}

1. H. M. H. Zakaly, H. A. Saudi, S. A. M. Issa, M. Rashad, A. I. Elazaka, H. O. Tekin, and Y. B. Saddeek, Ceram. Int. (2020).

2. S. A. M. Issa, M. Ahmad, H. O. Tekin, Y. B. Saddeek, and M. I. Sayyed, Results Phys. 13, 102165 (2019).

3. S. A. M. Issa, H. M. H. Zakaly, M. Pyshkina, M. Y. A. Mostafa, M. Rashad, and T. S. Soliman, Radiat. Phys. Chem. 180, 109281 (2021).

4. E. Kavaz, Radiat. Phys. Chem. 160, 112 (2019).

5. C. Pereira, F. C. Cassanjes, J. S. Barbosa, R. R. Gonçalves, S. J. L. Ribeiro, and G. Poirier, J. Non. 
Cryst. Solids 463, 158 (2017).

6. A. S. Yasukevich, G. E. Rachkovskaya, G. B. Zakharevich, E. E. Trusova, A. A. Kornienko, E. B. Dunina, V. E. Kisel, and N. V. Kuleshov, J. Lumin. 229, 117667 (2021).

7. S. Arunkumar and K. Marimuthu, J. Alloys Compd. 565, 104 (2013).

8. N. UVAROV, E. HAIRETDINOV, J. REAU, J. BOBE, J. SENEGAS, and M. POULAIN, Solid State Ionics 74, 195 (1994).

9. G. Lakshminarayana, K. M. Kaky, S. O. Baki, A. Lira, P. Nayar, I. V. Kityk, and M. A. Mahdi, J. Alloys Compd. 690, 799 (2017).

10. P. G. Prakash and J. L. Rao, J. Mater. Sci. 39, 193 (2004).

11. G. El-Damrawi, Phys. Status Solidi 177, 385 (2000).

12. A. WAGH, Y. RAVIPRAKASH, and S. D. KAMATH, Trans. Nonferrous Met. Soc. China 25, 2637 (2015).

13. G. Liao, Q. Chen, J. Xing, H. Gebavi, D. Milanese, M. Fokine, and M. Ferraris, J. Non. Cryst. Solids 355, 447 (2009).

14. S. Hayakawa, A. Osaka, H. Nishioka, S. Matsumoto, and Y. Miura, J. Non. Cryst. Solids 272, 103 (2000).

15. İ. Kabalcı, G. Özen, and M. L. Öveçoğlu, J. Raman Spectrosc. 40, 272 (2009).

16. V. Nazabal, S. Todoroki, S. Inoue, T. Matsumoto, S. Suehara, T. Hondo, T. Araki, and T. Cardinal, J. Non. Cryst. Solids 326-327, 359 (2003).

17. M. Arnaudov, V. Dimitrov, Y. Dimitriev, and L. Markova, Mater. Res. Bull. 17, 1121 (1982).

18. Y. B. Saddeek, K. A. Aly, K. S. Shaaban, A. M. Ali, M. M. Alqhtani, A. M. Alshehri, M. A. Sayed, and E. A. Abdel Wahab, J. Non. Cryst. Solids 498, 82 (2018).

19. E. F. El Agammy, H. Doweidar, K. El-Egili, and R. Ramadan, J. Mater. Res. Technol. 9, 4016 (2020).

20. Y. S. Rammah, I. O. Olarinoye, F. I. El-Agawany, A. El-Adawy, and E. S. Yousef, Ceram. Int. (2020).

21. P. Kaur, D. Singh, and T. Singh, Nucl. Eng. Des. 307, 364 (2016). 
22. H. O. Tekin, M. I. Sayyed, and S. A. M. Issa, Radiat. Phys. Chem. 150, 95 (2018).

23. H. O. Tekin, V. P. Singh, and T. Manici, Appl. Radiat. Isot. 121, 122 (2017).

24. A. M. A. Mostafa, H. M. H. Zakaly, M. Pyshkina, S. A. M. Issa, H. O. Tekin, H. A. A. Sidek, K. A. Matori, and M. H. M. Zaid, J. Mater. Res. Technol. 9, 12335 (2020).

25. H. O. Tekin, S. A. M. Issa, E. Kavaz, and E. E. Altunsoy Guclu, Mater. Res. Express 6, 115212 (2019).

26. M. S. Al-Buriahi, H. O. Tekin, E. Kavaz, B. T. Tonguc, and Y. S. Rammah, Appl. Phys. A Mater. Sci. Process. 125, 866 (2019).

27. A. M. A. Mostafa, S. A. M. Issa, H. M. H. Zakaly, M. H. M. Zaid, H. O. Tekin, K. A. Matori, H. A. A. Sidek, and R. Elsaman, Results Phys. 19, 103496 (2020).

28. M. Rashad, H. O. Tekin, H. M. Zakaly, M. Pyshkina, S. A. M. Issa, and G. Susoy, Nucl. Eng. Technol. 52, 2078 (2020).

29. O. I. Sallam, A. M. Madbouly, N. A. Elalaily, and F. M. Ezz-Eldin, J. Alloys Compd. 843, 156056 (2020).

30. A. M. A. Henaish, A. N. El-Sharkawy, S. A. Shama, O. M. Hemeda, and R. Ghazy, J. Phys. Conf. Ser. 1253, 012024 (2019).

31. A. I. Elazaka, H. M. H. Zakaly, S. A. M. Issa, M. Rashad, H. O. Tekin, H. A. Saudi, V. H. Gillette, T. T. Erguzel, and A. G. Mostafa, J. Hazard. Mater. 403, 123738 (2021).

32. A. M. A. Henaish, M. Mostafa, B. I. Salem, H. M. H. Zakaly, S. A. M. Issa, I. A. Weinstein, and O. M. Hemeda, J. Mater. Sci. Mater. Electron. 31, 20210 (2020).

33. H. M. Zakaly, A. S. Abouhaswa, S. A. M. Issa, M. Y. A. Mostafa, M. Pyshkina, and R. ElMallawany, J. Non. Cryst. Solids 543, 120151 (2020).

34. A. Makishima and J. D. Mackenzie, J. Non. Cryst. Solids 12, 35 (1973).

35. A. Makishima and J. D. Mackenzie, J. Non. Cryst. Solids 17, 147 (1975).

36. S. Khatir, F. Romain, J. Portier, S. Rossignol, B. Tanguy, J. J. Videau, and S. Turrell, J. Mol. Struct. 298, 13 (1993).

37. S. Inaba, S. Oda, and K. Morinaga, J. Non. Cryst. Solids 325, 258 (2003).

38. D. R. Lide, CRC Handbook of Chemistry and Physics: A Ready-Reference Book of Chemical and 
Physical Data (CRC press, 1995).

39. K. S. Thanthiriwatte, M. Vasiliu, S. R. Battey, Q. Lu, K. A. Peterson, L. Andrews, and D. A. Dixon, J. Phys. Chem. A 119, 5790 (2015).

40. V. Piacente, B. Brunetti, and P. Scardala, J. Chem. Eng. Data 55, 3731 (2010).

41. M. A. M. Uosif, A. M. A. Mostafa, S. A. M. Issa, H. O. Tekin, Z. A. Alrowaili, and O. Kilicoglu, J. Non. Cryst. Solids 532, 119882 (2020).

42. S. A. M. Issa, A. A. A. Darwish, and M. M. El-Nahass, Prog. Nucl. Energy 100, 276 (2017).

43. (n.d.). 
Figures

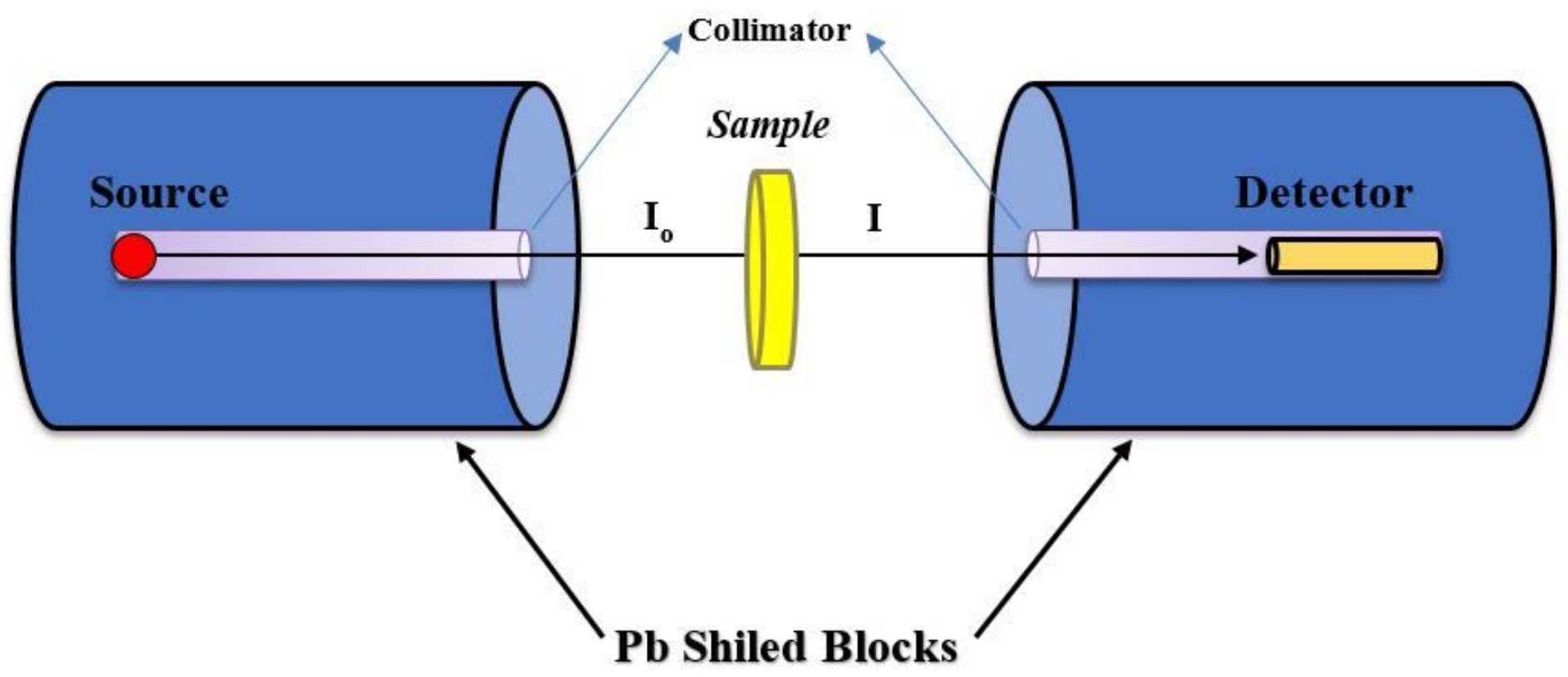

Figure 1

FLUKA Monte Carlo simulation setup used for mass attenuation coefficients calculations of glass samples. 


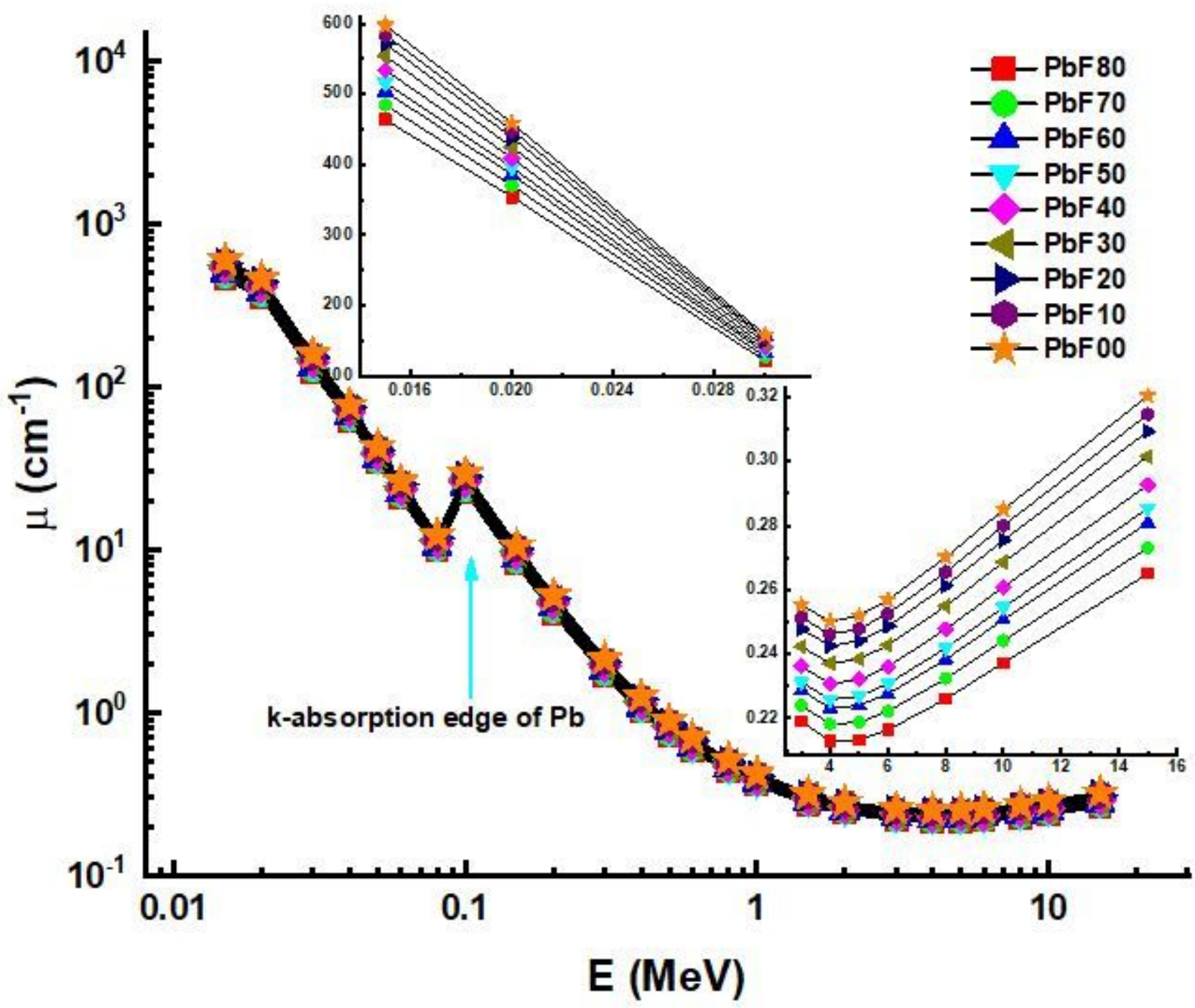

Figure 2

Variation of linear attenuation coefficient $(\mu)$ values versus photon energy $(E)$ for glass samples. 

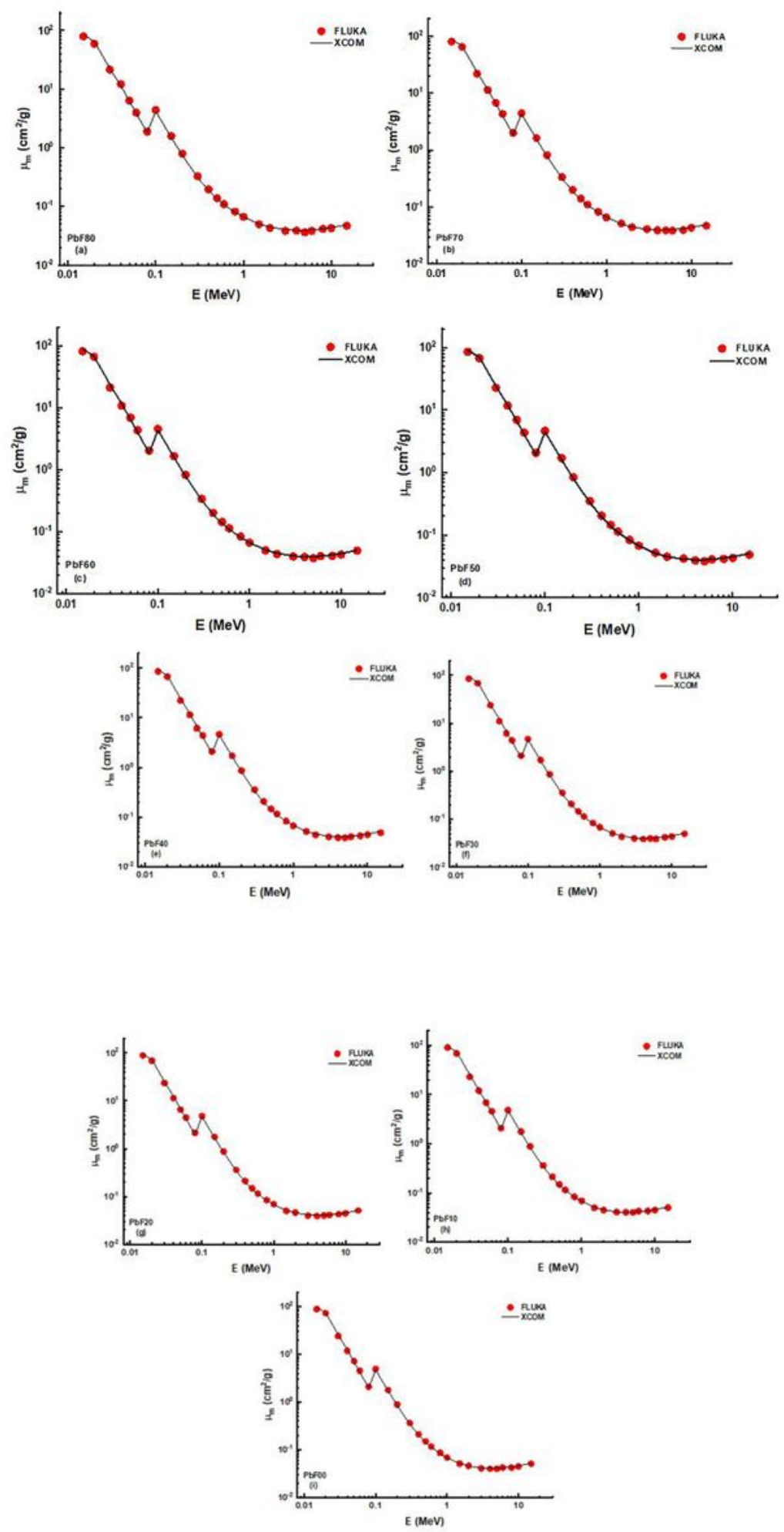

Figure 3

(a-i) Variation of mass attenuation coefficient $(\mu \mathrm{m})$ values versus photon energy $(E)$ for glass samples. 


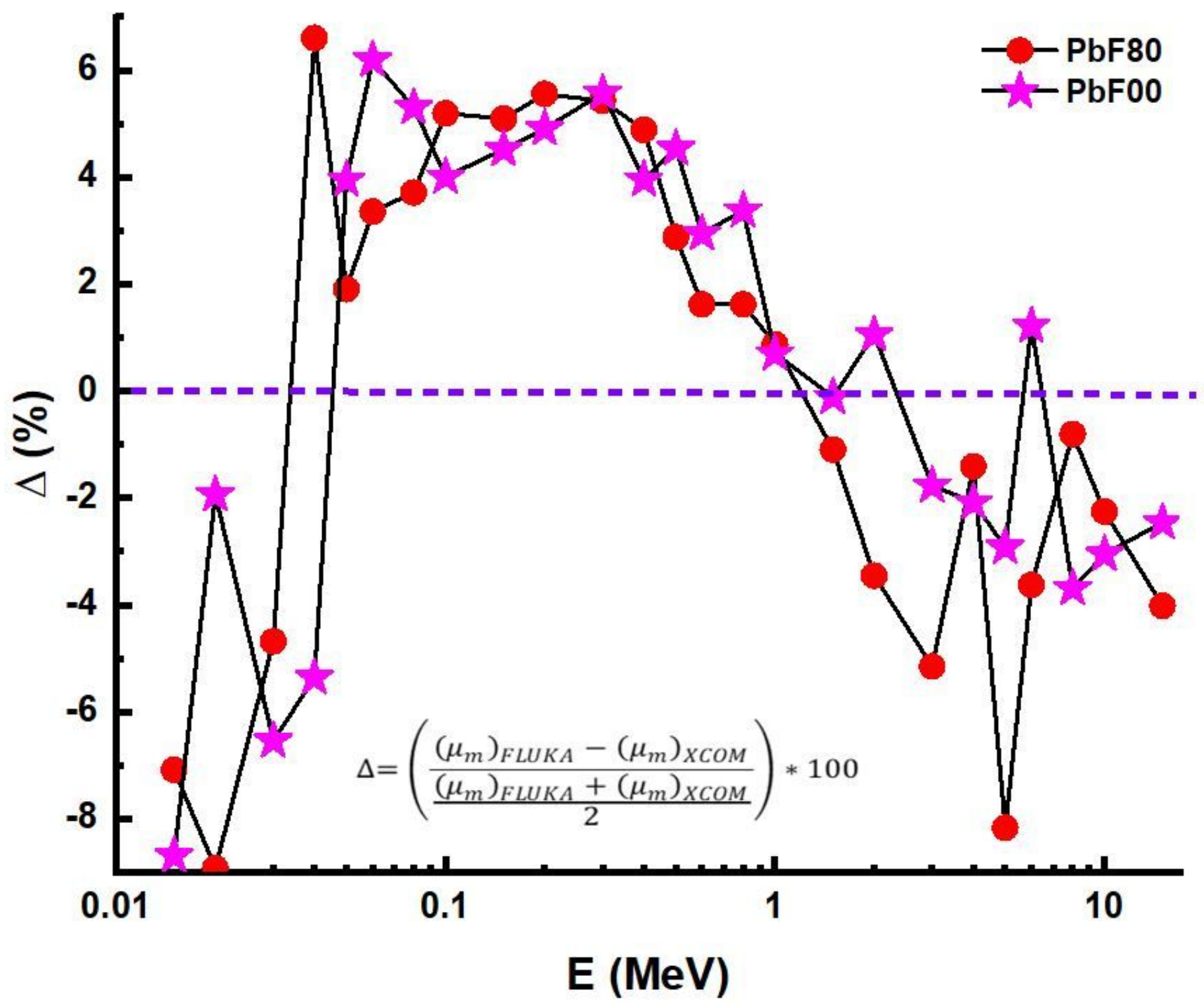

Figure 4

Difference $(\Delta)$ between FLUKA code and XCOM program for Pb80 and Pb00 glass samples 


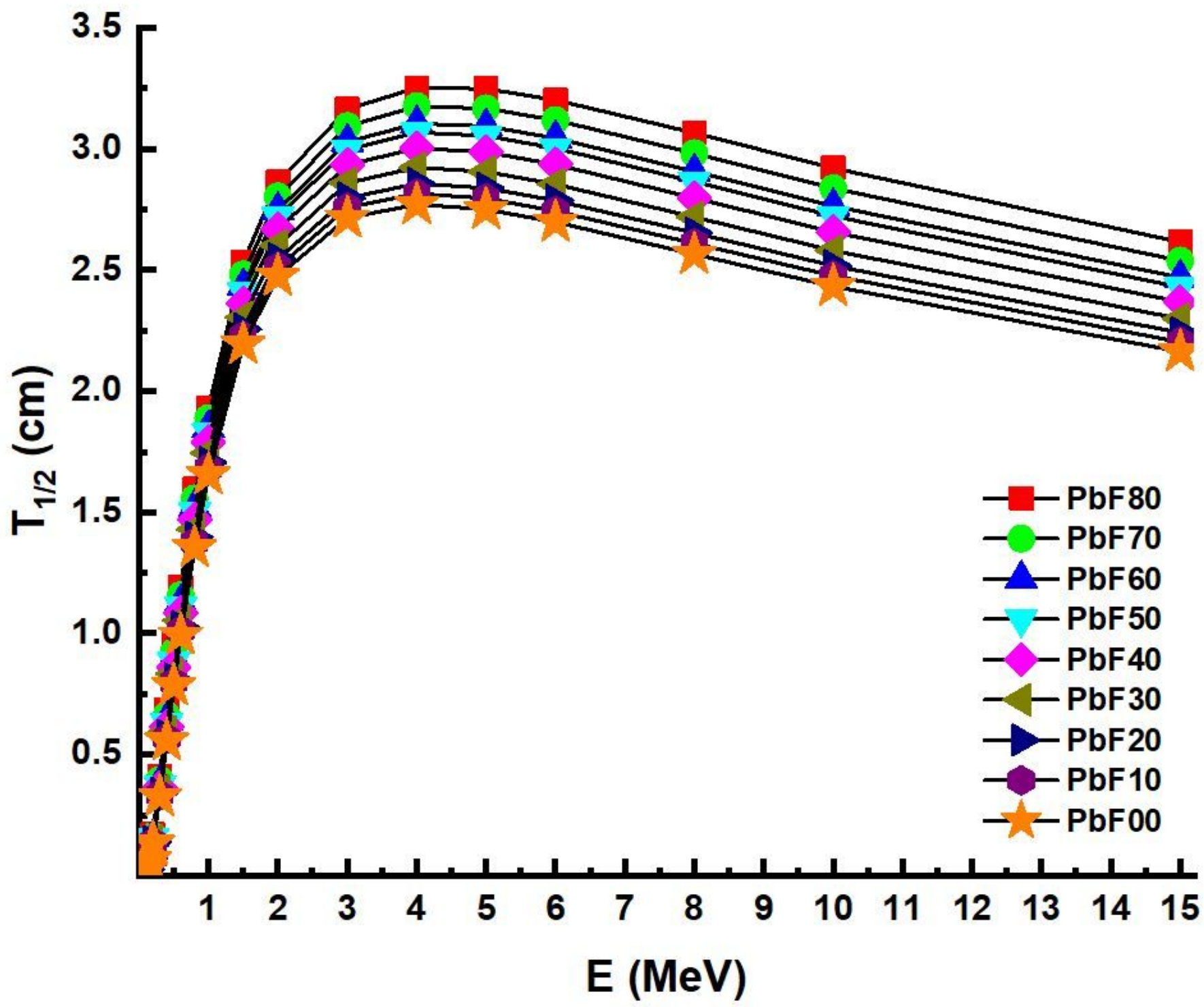

Figure 5

Variation of half-value layer ( $\mathrm{T} 1 / 2)$ values with photon energy for glass samples 


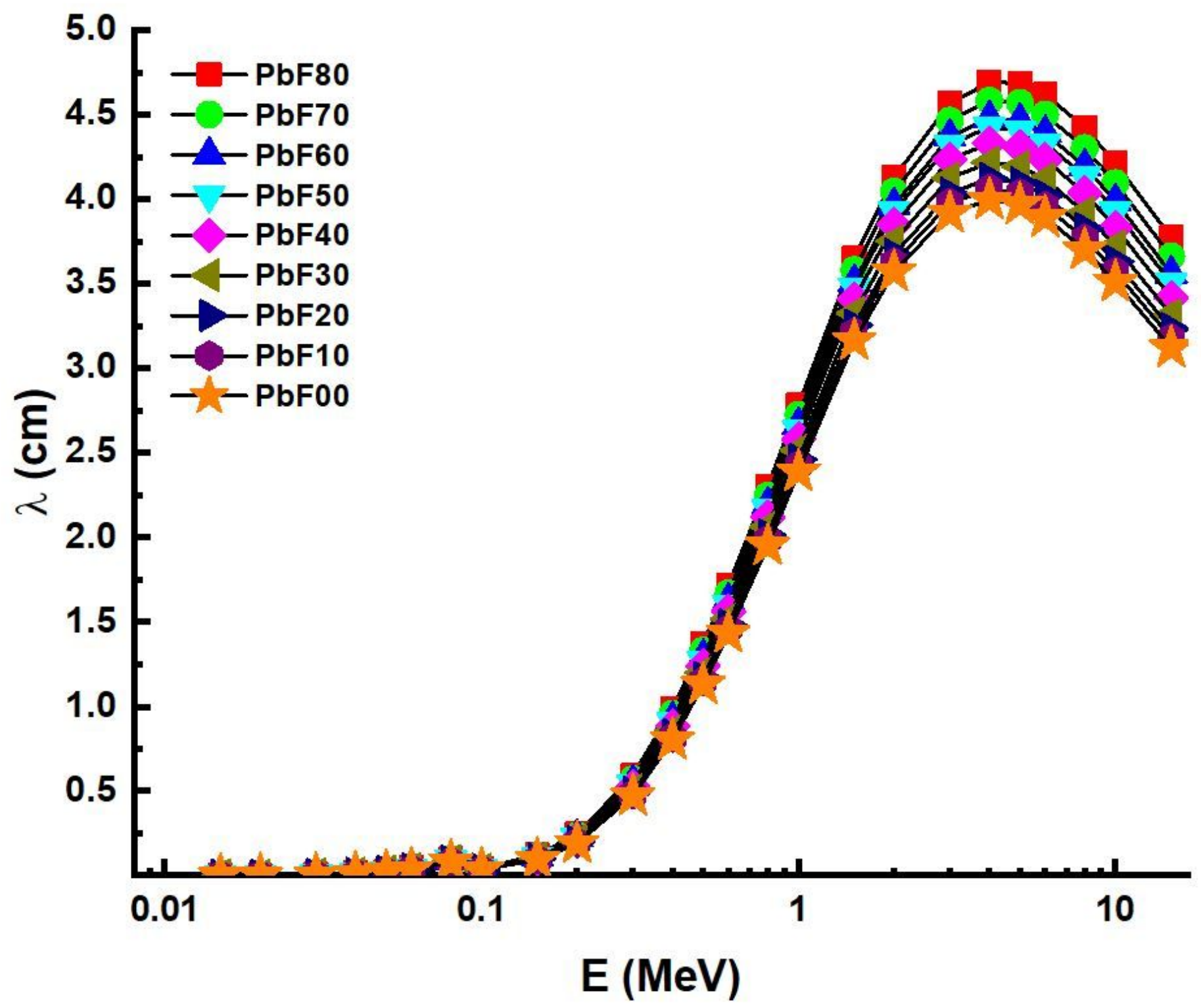

Figure 6

Variation of mean free path $(\lambda)$ values with photon energy for glass samples 


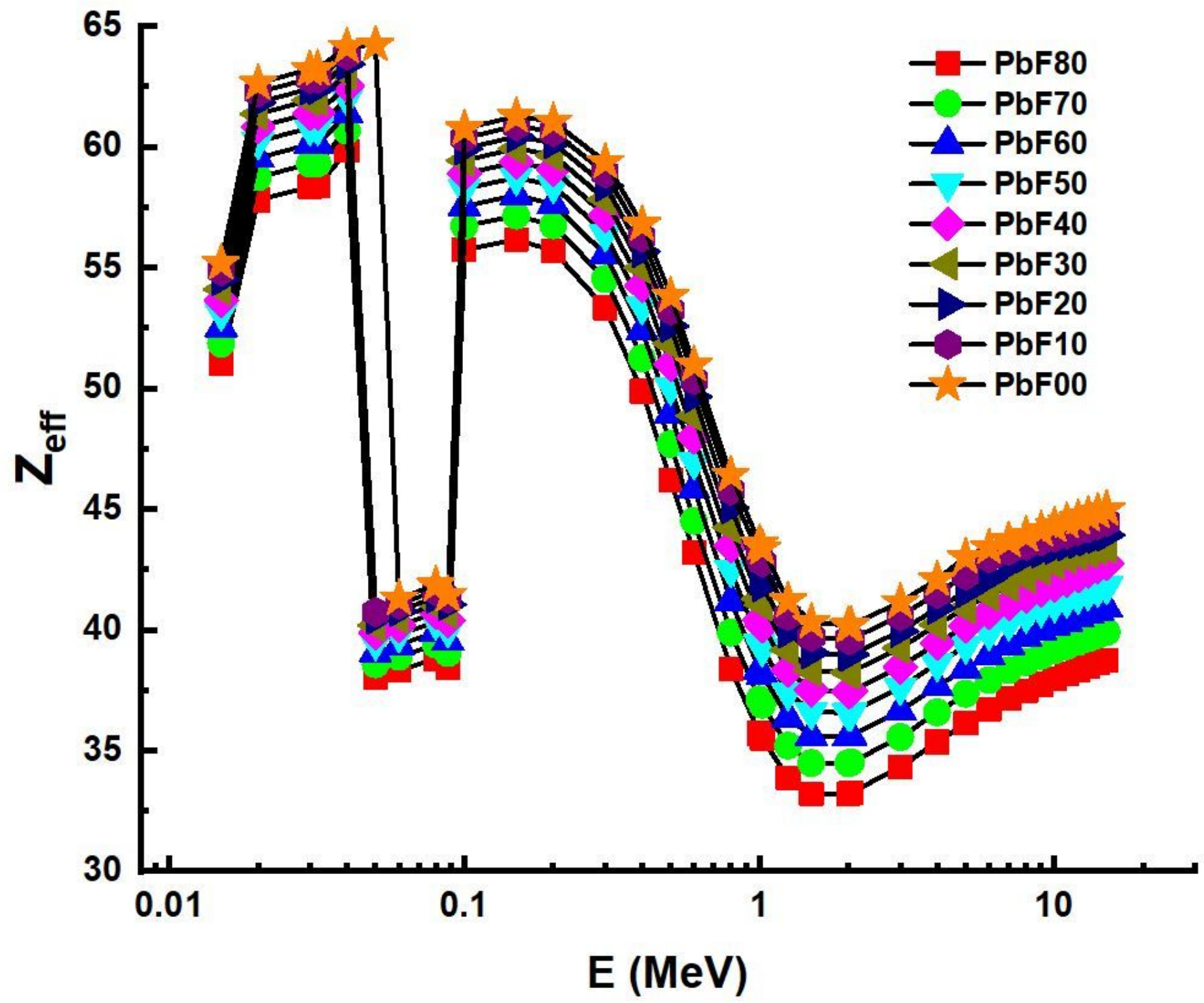

Figure 7

Variation of effective atomic number (Zeff) values with photon energy for glass samples 


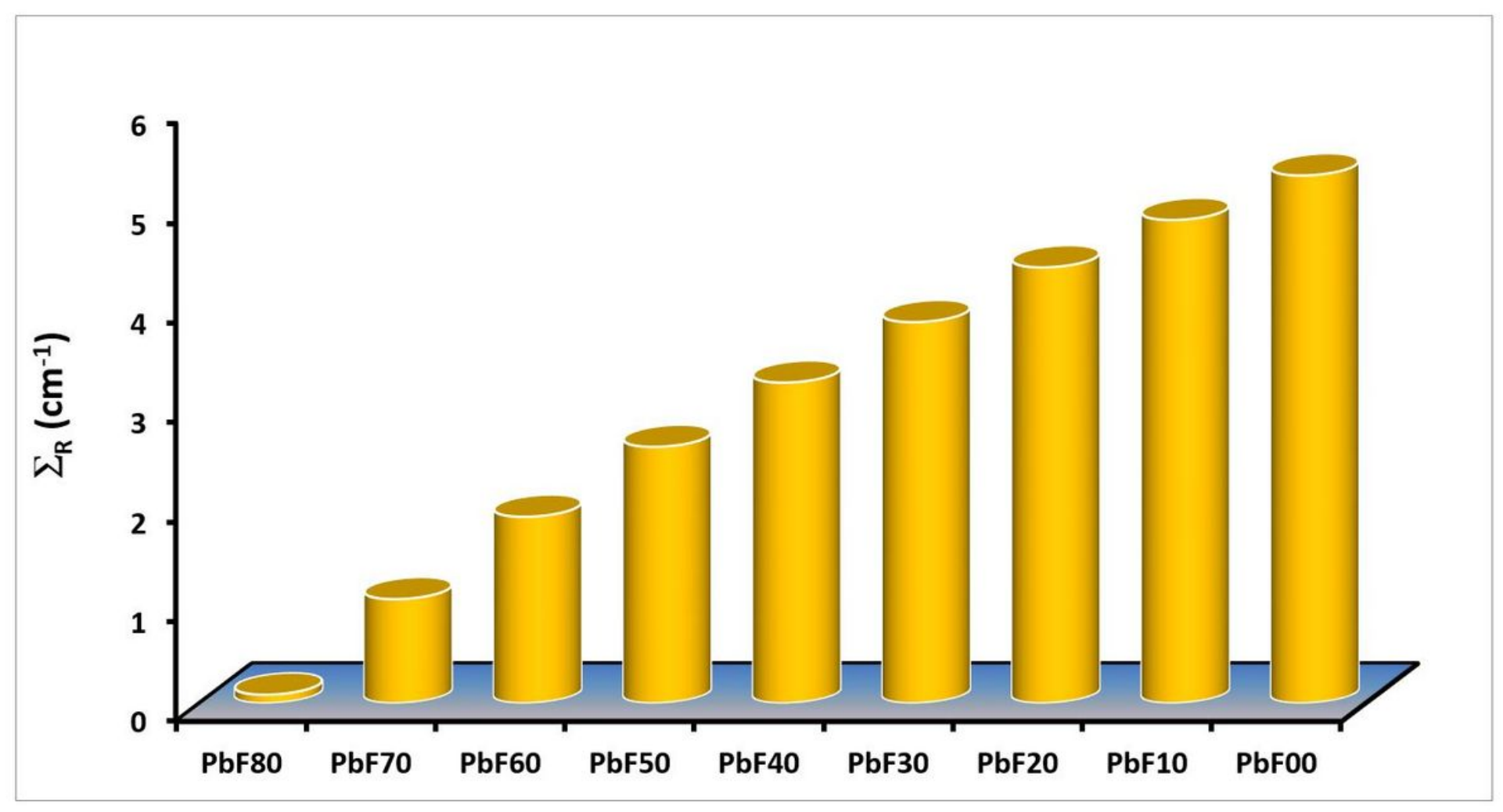

Figure 8

Effective removal cross-sections for fast neutrons ( $\Sigma R)$ for all glasses 